\title{
Review on Role of Nano-Micro Nutrients in Vegetable Crops
}

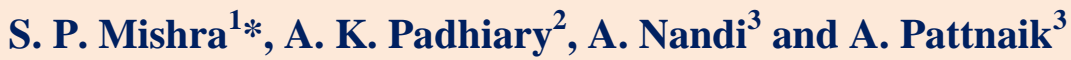 \\ ${ }^{1}$ Krishi Vigyan Kendra (OUAT), Jajpur, Odisha, India \\ ${ }^{2}$ Krishi Vigyan Kendra (OUAT) Chiplima, Sambalpur, 768026, Odisha, India \\ ${ }^{3}$ Dept. Vegetable Science, Odisha University of Agriculture and Technology, Bhubaneswar, \\ Odisha, India
}

*Corresponding author

\begin{abstract}
A B S T R A C T
Keywords

Fertilizer, Nano

Agriculture, Salt

Stress, Callus,

Nano-bentonite

Article Info

Accepted:

04 September 2019

Available Online:

10 October 2019

Nanotechnology has been defined as relating to materials, systems and processes which operate at a scale of $100 \mathrm{~nm}$ or less. Nanotechnology has many applications in all stages of production, processing, storing, packaging and transport of agricultural products. Nanotechnology will revolutionize agriculture and food industry by innovation new techniques such as: Precision farming techniques, enhancing the ability of plants to absorb nutrients, more efficient and targeted use of inputs, disease detection and control diseases, withstand environmental stress and effective systems for processing, storage and packaging.

\section{Introduction}

Indian Agriculture is facing a wide spectrum of constraints such as burgeoning population, shrinking farm land, restricted availability of water, imbalanced fertilizer application and low soil organic carbon, besides experiencing the fatigue of green revolution and vagaries of climate change. About 60 per cent of our agricultural land currently under cultivation suffers from indiscriminate use of chemical fertilizers and irrigation water (Palaniappan and Annadurai, 1999). Wider use of high

dose of fertilizers and insufficient application of organics led to negative impacts like (i) reduction in soil fertility (ii) destruction of soil structure, aeration and water holding capacity (iii) occurrence of micro nutrient deficiencies in many areas (iv) adverse effects on soil biotic life particularly in acidic soil ( $\mathrm{v}$ ) deterioration in taste of the food (vi) poisoning of food with highly toxic pesticide residues (vii) susceptibility of soil to erosion by wind and water and (viii) Pollution and health hazards for human beings.
\end{abstract}


In order to efficiently address many of the challenges ahead, we should think of an alternate technology such as "Nano technology" to precisely detect and deliver the correct quantity of nutrients or other inputs required by crops that promote productivity with environmental safety. The word "Nano agriculture" refers to the infusion of nano technology or concepts and principles in agricultural sciences so as to develop processes and products that precisely deliver inputs and promote productivity without associated environmental harm. Nano Agriculture is quite appropriate in India in the context of changing scenarios in agricultural production systems, which are on the verge of transformation towards precision agriculture. Nano-fertilizers are nutrient carriers of nanodimension ranging from $30-40 \mathrm{~nm}$ and capable of holding bountiful of nutrient ions due to their high surface area and releasing them slowly and steadily that commensurate with crop demands.

Siddique et al., (2015) studied the role of Nanoparticles in Plants. Nanotechnology opens a large scope of novel application in the fields of biotechnology and agricultural industries, because nanoparticles (NPs) have unique physicochemical properties, i.e., high surface area, high reactivity, tunable pore size, and particle morphology. Nanoparticles can serve as "magic bullets", containing herbicides, nano-pesticide fertilizers, or genes, which target specific cellular organelles in plant to release their content. Despite the plenty of information available on the toxicity of nanoparticles to plant system, few studies have been conducted on mechanisms, by which nanoparticles exert their effect on plant growth and development. Therefore, the present review highlights the key role of nanoparticles in plants. Moreover, nanoscience contributes new ideas leading us to understand the suitable mode of action of nanoparticles in plants. The appropriate elucidation of physiological, biochemical, and molecular mechanism of nanoparticles in plant leads to better plant growth and development.

\section{Growth and Development}

Ping et al., (2008) studied the effects of NanoTiO_2 Photosemiconductor on Photosynthesis of Cucumber Plants. The mechanism of $\mathrm{TiO} 2$ semiconductor photocatalysis had similarity with artificial photosynthesis. The effects of nano-TiO2 photosemiconductor sol on the photosynthesis of cucumber plants had been firstly reported in this paper. Anatase $\mathrm{TiO}_{2}$ semiconductor used in the experiment was synthesized by sol-gel methods and its effects on photosynthesis, activities of root systems and contents of leaf cell malondialdehyde had been studies after spray different concentration of nano- $\mathrm{TiO} 2$ sol on cucumber leaves in culturing experiments. The experimental results showed that nano- $\mathrm{TiO}_{2}$ sol could form perfectly adhesive, transparent, continuing and stable films on the surfaces of leaves by which net photosynthetic rates and activities of root system had been significantly promoted. These results provided some scientific and technical references for application of nanomaterials which using $\mathrm{TiO} 2$ as effective ingredients in agricultural research.

Jian et al., (2009) studied the Application Research of Nano-biotechnology to Promote Increasing of Vegetable Production. Nanobiotechnology was first used on crops in 2007 , when 5 to $50 \mathrm{~nm}$ of carbon was added to the fertilizer to forming Nano-fertilizer. The experiments of fertilizer efficiency on radish, cabbage, cabbage, eggplant, peppers, tomatoes, celery and leek crops were carried out for the past two years. The results showed that the fertilizer promoted the growth of the crops, come into the market 5 to 7 days ahead of time, and made the yield increase $20 \%$ to $40 \%$.After fertilization the white radish grew 
to $83 \mathrm{~cm}$ in 38 days, eggplant $1.2 \mathrm{~kg}$ in 20 days and so on. Nano-fertilizer could improve the quality of the vegetables. The content of VC in chili increased 1.5 times. Nano-carbon was proved to be non-toxic materials by the Chinese Center for Disease Control and Prevention.

\section{Fertilizer Use Efficiency}

Shujuan et al., (2011). Nano-preparation on Growth and Nitrogen Fertilizer Use Efficiency of Cabbage. In order to improve the fertilizer use efficiency, research and develop environment-friendly fertilizers, which can control the agricultural nonpoint source pollution from the source, a soil pot experiment was taken to study the effects of nano-preparation on the production, nutrient absorption, nitrogen fertilizer use efficiency, leaf chlorophyll content and some quality indexes of cabbage. The results showed that, the production, leaf chlorophyll content,the amount of nutrients $(\mathrm{N}, \mathrm{P}, \mathrm{K})$ absorption and nitrogen fertilizer use efficiency of cabbage were increased by adding nano-hydroquinone and nano-tea-polyphenols in nitrogen fertilizer, and the higher adding amount of nano-preparation had a more obvious effect. The best effective treatment among the four nano-preparation treatments was the one with $4 \%$ tea-polyphenols. The production and nitrogen fertilizer use efficiency of cabbage were increased by $44.5 \%$ and $134.1 \%$, respectively. However, the effect of adding nano-preparation on the quality of cabbage was different, the changes of soluble sugar content were little, the nitrate content was increased and the $\mathrm{Vc}$ content had a increasing trend. The content of $\mathrm{Vc}$ had no change in the treatment $4 \%$ tea-polyphenols while its dry weight increment was the highest. In short, nano-preparation could increase crop yields and improve the fertilizer efficiency.

Juan et al., (2011). Studied the effects of nano-bentonite coated urea on growth and nitrogen use efficiency of cabbage. A soil pot experiment was taken to study the effects of Nano-bentonit coated urea on the yield, nutrient absorption, nitrogen fertilizer use efficiency, leaf chlorophyll content and quality indexes of cabbage. The results showed that nano-bentonit coated urea could significantly improve the yield of cabbage and the accumulation of nutrients, so as the nitrogen use efficiency. Comparing with pure urea, the treatments applied 15\% nano-bentonit coated urea while the content of nitrogen decreased about $10 \%$ and $20 \%$, the nitrogen use efficiency has also been respectively improved about $7.9 \%, 8.3 \%$; the treatments applied $20 \%$ nano-bentonit coated urea while the content of nitrogen decreased about $10 \%$ and $20 \%$,the nitrogen use efficiency respectively improved about $3.6 \%, 12.6 \%$. The cabbage chlorophyll content of all the nitrogen treatments are significantly higher than that of the nonnitrogen treatments, and cabbage chlorophyll content in the treatments applied nanobentonite coated urea was higher than that in the treatment applied conventional urea, but the difference was not significant. Kale and Gawade (2016). Studied the on nanoparticle induced nutrient use efficiency of Fertilizer and crop productivity. The experiment was carried out in randomize dblock design with three replications. The first treatment (T-1), comprised of recommended dose of fertilizer (RDF), N: P: K (50:50:50), applied at the time of transplantation. The second treatment (T-2) was conducted with RDF in combination @ $2 \mathrm{~kg} \mathrm{ZnSO}$ (bulk)/ha. The third treatment (T3) was added, N: P: K $(12.5 ; 12.5 ; 12.5)$ in combination to ZnO NP @ 4500mg/ha.

The forth treatment (T-C) was without any fertilizer. All treatments were given appropriate quantity of nitrogen per hectare as urea at the 30th day of transplantation. The combination N: P: K $(12.5 ; 12.5 ; 12.5)$ and $\mathrm{ZnO} \mathrm{NP} @ 4500 \mathrm{mg} / \mathrm{ha}$ yielded $91 \%$ and $45.3 \%$ higher brinjal yield and biomass respectively than the treatment with only 
RDF. It was also observed that $38 \%$ and $21 \%$ higher yield and biomass respectively were recorded in the treatment where combination of RDF with $\mathrm{ZnSO} 4$ (bulk) over RDF was used alone. The results of field trials reveal that, there was synergistic effect of $\mathrm{ZnO} \mathrm{NP}$ @ 4500mg per hectare with $\mathrm{N}$ : P: K complex fertilizer on growth attributes of brinjal as well as nutrient use efficiency.

\section{Enzyme activity}

Bo et al., (2012) studied the physiological effects under the condition of spraying nanoSiO_2 onto the Indocalamus barbatus McClure leaves. Physiological effects under the condition of spraying different concentrations $(0,150,300,450 \mathrm{mg} / \mathrm{L})$ of nano-SiO_2 onto the Indocalamus barbatus McClure leaves were studied. The results showed that all concentrations of nano-SiO_2 treatments could increase the contents of soluble protein, free amino acids, total nitrogen, phosphorus, potassium, stimulate SOD and POD activities, and decrease MDA content. Certain correlation of concentration and time would affect the effects.300 mg/L nano-SiO_2 treatment got the best effect which indicated that $300 \mathrm{mg} / \mathrm{L}$ nano-SiO_2 treatment could effectively increase the nutritional function and the ability of scavenging active oxygen in Indocalamus barbatus leaves and improve the physiological function of leaves.

\section{Nutrient uptake}

Roosta et al., (2015) studied the effect of Nano Fe-Chelate, Fe-Eddha and $\mathrm{FeSO}_{4}$ on Vegetative Growth, Physiological Parameters and Some Nutrient Elements Concentrations of Four Varieties of Lettuce (Lactuca sativa L.) In NFT System. In order to investigate the effects of different iron $(\mathrm{Fe})$ sources (nano iron $(\mathrm{Fe})$-chelate, Fe- ethylenediamine-di(ohydroxy phenyl acetic acid (EDDHA) and iron
(II) sulfate $\left(\mathrm{FeSO}_{4}\right)$ ) on lettuce (Lactuca sativa) growth in alkaline solutions, an experiment was arranged in hydroponic system. This study showed that leaf Fe content and overall plant growth was significantly increased by Fe-chelate application, and the highest values of leaf $\mathrm{Fe}$, plant pigments and vegetative growth were recorded in plants treated with nano Fe-chelate. The lowest Fe, chlorophyll, carotenoids and soluble sugars in leaves were observed in $\mathrm{FeSO}_{4}$ treatment. There were no difference in soluble sugars contents of plants between nano Fe-chelate and Fe-EDDHA treatments. Fertilization of lettuce plants with different Fe-chelate sources had a beneficial effect on the manganese (Mn) and zinc $(\mathrm{Zn})$ uptake in plants. It is concluded that application of chelated form of $\mathrm{Fe}$ (especially nano Fe-chelate) must be performed in hydroponic system with alkaline water, to overcome $\mathrm{Fe}$ deficiencies and to make better nutritional status.

Vercelli et al (2015) studied the effect of Fenanosponge complex in horticulture. Iron deficiency is a major nutritional disorder in crops. Inorganic Fe-compounds and synthetic Fe-chelates are commonly used to control chlorosis but their use arise environmental concerns.

We recently developed a new iron fertilizer using a $\beta$-cyclodextrin-based nanosponge complex (Fe-NS). In this study, a pilot trial was performed on hydroponically cultivated horticultural plants in order to evaluate the effect of Fe-NS. Sweet corn and tomato were used as model plants analyzing chlorophyll, dry matter and Fe content. Fe-NS effect was compared to FeSO4 and Fe-DTPA. Fe-NS had a positive effect on re-greening and growth in sweet corn and tomato plants.

\section{Callus culture}

Alharby et al., (2016). Studied the effect of application of zinc oxide nanoparticles on callus 
induction, plant regeneration, element content and antioxidant enzyme activity in tomato (Solanum lycopersicum mill.) under salt stress. The properties of nanomaterials and their potential applications have been given considerable attention by researchers in various fields, especially agricultural biotechnology. However, not much has been done to evaluate the role or effect of zinc oxide nanoparticles ( $\mathrm{ZnO}-\mathrm{NPs})$ in regulating physiological and biochemical processes in response to salt induced stress.

For this purpose, some callus growth traits, plant regeneration rate, mineral element (sodium, potassium, phosphorous and nitrogen) contents and changes in the activity of superoxide dismutase (SOD) and glutathione peroxidase (GPX) in tissues of five tomato cultivars were investigated in a callus culture exposed to elevated concentrations of salt $(3.0$ and $6.0 \mathrm{~g} \mathrm{~L}$ $1 \mathrm{NaCl}$ ), and in the presence of zinc oxide nanoparticles (15 and $30 \mathrm{mg} \mathrm{L}-1$ ). The relative callus growth rate was inhibited by $3.0 \mathrm{~g} \mathrm{~L}$ $1 \mathrm{NaCl}$; this was increased dramatically at $6.0 \mathrm{~g}$ $\mathrm{L}-1$. Increasing exposure to $\mathrm{NaCl}$ was associated with a significantly higher sodium content and SOD and GPX activities. Zinc oxide nanoparticles mitigated the effects of $\mathrm{NaCl}$, and in this application of lower concentrations (15 mg L-1) was more effective than a higher concentration (30 mg L-1). This finding indicates that zinc oxide nanoparticles should be investigated further as a potential anti-stress agent in crop production. Different tomato cultivars showed different degrees of tolerance to salinity in the presence of $\mathrm{ZnO}-\mathrm{NPs}$. The cultivars Edkawy, followed by Sandpoint, were less affected by salt stress than the cultivar Anna Aasa.

\section{Fruit quality}

Zhao et al., (2016) studied $\mathrm{CeO}_{2}$ and $\mathrm{ZnO}$ Nanoparticles Change the Nutritional Qualities of Cucumber (Cucumis sativus). There is lack of information about the effects of nanoparticles (NPs) on cucumber fruit quality. This study aimed to determine possible impacts on carbohydrates, proteins, mineral nutrients, and antioxidants in the fruit of cucumber plants grown in soil treated with $\mathrm{CeO}_{2}$ and $\mathrm{ZnO}$ NPs at 400 and $800 \mathrm{mg} / \mathrm{kg}$. Fourier transform infrared spectroscopy (FTIR) was used to detect changes in functional groups, while ICP-OES and $\mu$-XRF were used to quantify and map the distribution of nutrient elements, respectively. Results showed that none of the $\mathrm{ZnO}$ NP concentrations affected sugars; however at $400 \mathrm{mg} / \mathrm{kg}$, $\mathrm{CeO}_{2}$ and $\mathrm{ZnO}$ NPs increased starch content. Conversely, $\mathrm{CeO}_{2}$ NPs did not affect starch content but impacted nonreducing sugar content (sucrose). FTIR data showed changes in the fingerprint regions of 1106, 1083, 1153, and 1181, indicating that both NPs altered the carbohydrate pattern. ZnO NPs did not impact protein fractionation; however, $\mathrm{CeO}_{2} \mathrm{NPs}$ at 400 $\mathrm{mg} / \mathrm{kg}$ increased globulin and decreased glutelin. Both $\mathrm{CeO}_{2}$ and $\mathrm{ZnO}$ NPs had no impact on flavonoid content, although $\mathrm{CeO}_{2} \mathrm{NPs}$ at 800 $\mathrm{mg} / \mathrm{kg}$ significantly reduced phenolic content. ICP-OES results showed that none of the treatments reduced macronutrients in fruit. In case of micronutrients, all treatments reduced Mo concentration, and at $400 \mathrm{mg} / \mathrm{kg}, \mathrm{ZnO}$ NPs reduced $\mathrm{Cu}$ accumulation. $\mu-\mathrm{XRF}$ revealed that $\mathrm{Cu}, \mathrm{Mn}$, and $\mathrm{Zn}$ were mainly accumulated in cucumber seeds. To the best of the authors' knowledge this is the first report on the nutritional quality of cucumber fruit attributed to the impact of $\mathrm{CeO} 2$ and $\mathrm{ZnO}$ NPs.

Khot et al., (2012), studied the applications of nanomaterials in agricultural production and crop Protection.

Recent manufacturing advancements have led to the fabrication of nanomaterials of different sizes and shapes. These advancements are the base for further engineering to create unique properties targeted toward specific applications.

Historically, various fields such as medicine, environmental science, and food processing have employed the successful and safe use of nanomaterials. 
However, use in agriculture, especially for plant protection and production, is an under-explored area in the research community.

Preliminary studies show the potential of nanomaterials in improving seed germination and growth, plant protection, pathogen detection, and pesticide/herbicide residue detection. This review summarizes agricultural applications of nanomaterials and the role these can play in future agricultural production.

\section{References}

Ping Z,Haixin C, Zhijuan Z, Rugang Z. (2008 ). Effects of Nano-TiO ${ }_{2}$ Photosemiconductor on Photosynthesis of Cucumber Plants, Journal of Northeast Forestry University. 2008-08

Jian L, Yang-de Z, Zhi-ming. (2009). The Application Research of Nanobiotechnology to Promote Increasing of Vegetable Production, Hubei Agricultural Sciences. 2009-01

Shujuan W, Qiang L, Haixing S, Xiangmin R, Jianwei P, Xiaojuan W, Zhenhua Z, Lijun C.(2011). Effects of Nanopreparation on Growth and Nitrogen Fertilizer Use Efficiency of Cabbage, Chinese Agricultural Science Bulletin. 2011-13

Shu-juan W, Qiang L, Hai-xing S, Xiang-min R, Jian-wei P, Xiao-juan W (2011). Effects of nano-bentonite coated urea on growth and nitrogen use efficiency of cabbage, Journal of Hunan Agricultural University (Natural Sciences), Bo L,
Gongsheng $\mathrm{T}$, Yinfeng $\mathrm{X}$, Xianlei $\mathrm{C}$. (2012). The effect of nano-SiO 2 onto the Indocalamus barbatus McClure leaves, 2011-04

Khota LR, Sankarana S, Majaa JM, Ehsania R. (2012). The Applications of nanomaterials in agricultural production and crop protection: A review, Crop Protection 35 (2012) 64-70.

Siddique MH., Al-Whaibi MH., Firoz M.(2015). Role of Nanoparticles in Plants, springer International publishing, Switzerland.

Vercelli M, Gaino W, Contartese V, Gallo L, Tumiatti V, Larcher F, Scariot V. (2015). The effect of Fe-nanosponge complex in horticulture, Acta Sci. Pol. Hortorum Cultus, 14(2)2015, 51-58.

Alharby HF, Metwali EMR, Fuller MP, AldhebiyaniAY (2016). The Impact of application of zinc oxide nanoparticles on callus Induction, plant regeneration, element content and antioxidant Enzyme activity in tomato (Solanum lycopersicum mill.) Under salt Stress, Arch Biol Sci. 2016; 68(4):723-735

Zhao L, Peralta-Videa Jose R, Rico CM. (2016). The effect of $\mathrm{CeO} 2$ and $\mathrm{ZnO}$ Nanoparticles Change the Nutritional Qualities of Cucumber (Cucumis sativus), J. Agric. Food Chem.2014, 62, 2752-2759.

Kale AP, Gawade SN. (2016). Studies on nanoparticle induced nutrient use efficiency of fertilizer and crop productivity, Green Chemistry \&Technology Letters, Vol 2, No 2.

\section{How to cite this article:}

Mishra, S. P., A. K. Padhiary, A. Nandi and Pattnaik, A. 2019. Review on Role of Nano-Micro Nutrients in Vegetable Crops. Int.J.Curr.Microbiol.App.Sci. 8(10): 277-282.

doi: https://doi.org/10.20546/ijcmas.2019.810.029 